\title{
Offshore wind power integration to support weak grid voltage for industrial loads using VSC-HVDC transmission system
}

\author{
Ahmed A. Daoud, Ahmed F. Abouzeid, Sobhy S. Dessouky \\ Department of Electrical Power Engineering, Port-Said University, Port-Said, Egypt
}

\begin{tabular}{|c|c|}
\hline Article Info & ABSTRACT \\
\hline & \multirow{6}{*}{$\begin{array}{l}\text { This paper investigates the integration of the offshore wind power plant into } \\
\text { the grid using voltage source converter high-voltage direct current (VSC- } \\
\text { HVDC). The paper proposes both offshore and onshore converter stations } \\
\text { control to support voltage variation in grid. Heavy industrial loads result in a } \\
\text { weak grid. In this paper, the effect on industrial loads by the grid strength is } \\
\text { shown. Then the paper proposes a solution for the grid voltage support for } \\
\text { industrial loads connected to weak grids. The results showed that the increase } \\
\text { of grid voltage from } 0.7 \text { pu to } 1 \mathrm{pu} \text { at full load condition that provides a } \\
\text { continuous operation without any interruption. The system was modelled } \\
\text { using MATLAB/Simulink package. }\end{array}$} \\
\hline Received Jun 14, 2020 & \\
\hline Revised Dec 19, 2020 & \\
\hline Accepted Dec 30, 2020 & \\
\hline Keywords: & \\
\hline $\begin{array}{l}\text { Grid integration } \\
\text { HVDC transmission }\end{array}$ & \\
\hline
\end{tabular}

This is an open access article under the CC BY-SA license.

Vector control

Voltage-source converter

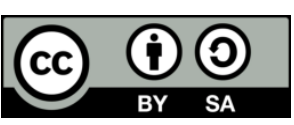

\section{Corresponding Author:}

Ahmed A. Daoud

Electrical Engineering Department

Port Said University

Port Fouad, Port Said, 42523, Egypt

Email: a.daoud@psu.edu.eg

\section{INTRODUCTION}

The demand increase in recent decades force most utilities to implement reliable and clean forms of energy rather than the conventional sources. Wind energy is the fastest grown among all renewable energy sources. Wind energy reaches approximately $670 \mathrm{GW}$ of cumulative worldwide renewable energy capacity [1]. Different locations of wind farm and season changes resulted in a wide variation of generated power, due to the nature of wind profile. The density of wind usually increased far from cities in remote locations like offshore and desert which means more cost. Environmental advantage of remote locations is gained due to reduction of noise (rotor blade noise) and visual impact.

For long distance more than $50 \mathrm{~km}$, the more feasible solution of bulk power transmission is high voltage direct current (HVDC) transmission with lower electrical losses. Two converter types namely: current source converter (CSC), which uses line-commutated switching devices (thyristors), called (LCCHVDC) and voltage source converter (VSC), which uses self-commutated switching devices such as IGBT, MOSFET, and GTO, called (VSC-HVDC) are used to build HVDC transmission systems. Various HVDC configurations are summarized in [2], according to the function and location of the converter station. The basic structure and control topologies are discussed in literature [3, 4].

Industrial power systems are characterized by heavily inductive loads which causes a voltage sag/dip on the grid. This voltage sag occurs when the grid is not strong enough to supply the loads with the required reactive power. Voltage sags and other grid disturbances can cause loads to mal-operation that can lead to high cost $[5,6]$. Different solutions have been suggested to solve the power quality problems in industrial systems. For small loads, voltage interruptions and dips can be over rided by using uninterruptible 
power supply (UPS) [7]. However, generation and absorption of reactive power can be provided in a faster rate using (STATCOM) than classical solutions. Using STATCOM mitigate flickers and reduce stability problems $[3,8,9]$. In this paper, the offshore wind power plant (WPP) grid integration using VSC-HVDC is investigated. In addition, the performance evalution of the industrial power system when supplied through VSC-HVDC is evaluated.

\section{SYSTEM DESCRIPTION}

Figure 1 shows the typical two-terminal VSC-HVDC system that connects an offshore WPP of $300 \mathrm{MW}$ rating to the main grid through a $100 \mathrm{Km}$ HVDC transmission cables. Wind turbines are assumed to gain maximum power through full control. The offshore WPP sending end is represented as an AC source. This paper main goal is to study the performance analysis of integrated power to the grid through the HVDC transmission system. Table 1 gives the system parameters while the system main components are described as.

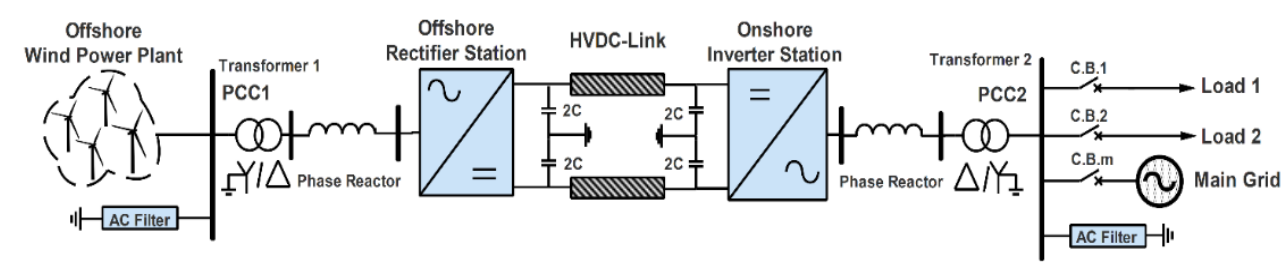

Figure 1. Schematic diagram of offshore wind power plant grid integration via VSC-HVDC

Table 1. Proposed system parameters

\begin{tabular}{cccc}
\hline Parameter & Value & Parameter & Value \\
\hline Nominal Power, $\mathrm{S}_{\mathrm{N}}$ & $300 \mathrm{MVA}$ & DC-cable parameters $(\mathrm{R}, \mathrm{L}, \mathrm{C})$ & $0.0146 \Omega / \mathrm{km}, 0.158 \mathrm{mH} / \mathrm{km}$, \\
& & & $0.275 \mu \mathrm{F} / \mathrm{km}$ \\
Nominal AC voltage (RMS), $\mathrm{V}_{\mathrm{T}}$ & $220 \mathrm{kV}$ & DC-link capacitor, CDC & $100 \mu \mathrm{F}$ \\
Grid frequency, $\mathrm{f}_{\mathrm{n}}$ & $50 \mathrm{~Hz}$ & Phase reACtors, $\mathrm{R}_{\mathrm{C}}, \mathrm{L}_{\mathrm{C}}$ & $1 \%, 15 \%$ \\
Switching frequency, $\mathrm{f}_{\mathrm{SW}}$ & $2.5 \mathrm{kHz}$ & Coupling transformers, $\mathrm{R}_{\mathrm{tr}}, \mathrm{L}_{\mathrm{tr}}$ & $0.5 \%, 15 \%$ \\
DC-link Voltage, VDC/2 & $150 \mathrm{kV}$ & High-pass filter reACtive compensation & 3rd, 50th order \\
\hline
\end{tabular}

\subsection{Converter stations}

A convereter station with two-leve sinusoidal pulse-width modulation (SPWM) is used for both machine side and grid side stations. Each station has anti-parallel free wheeling diodes with six IGBTs for switching purpose. The two components are integrated in the same package to allow current capacbilities in reverese direction and to prevent reverse voltage application. To apply current control and voltage withstanding ability in large power, a combination of both parallel and series IGBTs modules are used. For instance, 300 series IGBTs modules are used in the original $150 \mathrm{kV} \mathrm{HVDC}$ light schemes [10].

\subsection{Coupling transformer}

A 350 MVA $\Delta$-Y grounded transformer has been used. This will eliminate the third harmonic generated by the converter. This transformer maintains well-grounded system even in case of distributed generation islanding [11-13]. To avoid the size and weight issues, three single-phase transformers are used to support large power transmission.

\subsection{Phase reactor}

The phase reactor acts as a filter for the harmonic content produced by the converter switching. The main purpose of the reactor is to avoid short circuit occuurance between the grid and the converter. Independent control of transmitted active and reactive power will be provided by controlling the voltage drop and current direction across the phase reactor. An inductor with a very small series resistance form the phase reactor taking into account reactor losses. The typical impedance of the phase reactor is between $0.1-0.25 \mathrm{p} . \mathrm{u}[14,15]$.

\subsection{AC filter}

Converter stations output voltage and current have higher order harmonics other than the fundamental. Higher order harmonics if flowed through the grid would cause additional losses and distorted 
voltage waveforms. PWM allows switching harmonics to be shifted to higher frequency range. A passive high-pass AC filter is used in order to eliminate higher-order harmonics other than the fundamental.

\subsection{DC-link capacitor bank}

Two capacitor stacks forms the DC side. The middle point of the DC capacitor stacks is grounded. The DC capacitor is keeping the power balance during transients and acts as a temporary energy storage. Voltage ripples are reduced through DC link and this link provides sufficiently stable direct-voltage. Capacitor stack size depends mainly on the rated power transfer $\left(S_{n}\right)$ and the time rate change $(\tau)$ of the energy $(W)$ transferred into or out of the storage device. A $15 \mathrm{~ms}$ time constant $(\tau)$ was chosen for minimum capacitor value calculation. As shown in (1) and (2) give the amount of energy transferred through the DC link.

$$
\begin{aligned}
& W=\tau \cdot S_{n}=\frac{1}{2} C V_{d c}^{2} \\
& C=\frac{2 \tau \cdot S_{n}}{V_{d c}^{2}}
\end{aligned}
$$

\subsection{DC cables}

For VSC-VHDC transmission, XLPE polymer extruded cables are preferred for their mechanical strength, low weight and flexibility. The modeling used of such cables is a $\pi$-model. Two identical capacitors $\mathrm{C}_{\text {pole }} / 2$ each at both sides of the model while the impedance consists of resistance $\mathrm{R}_{\text {pole }}$ and inductance $\mathrm{L}_{\text {pole }}$ [16].

\section{MODELLING AND CONTROL}

The vector control is a well-known method. This control method is widely used in VSC-driven electrical machines [17-19]. In this paper, the model under consideration uses the vector control on d-q synchronous reference frame as:

\section{1. d-q synchronous reference frame for VSC-model}

Figure 2 shows the direction of power transferred to the DC link from the grid through converter reactor $\left(\mathrm{R}_{\mathrm{C}}, \mathrm{L}_{\mathrm{C}}\right)$. Where, $\mathrm{R}_{\mathrm{C}}$ represents the total resistance, and $\mathrm{L}_{\mathrm{C}}$ represents the total inductance of the filter and transformer windings. As shown in (3), the voltage drop value across the phase reactor $V_{L}(t)$. $V_{L}(t)$ represents the three-phase grid voltage at PCC (point of common coupling), while the converter output voltage is given by $V_{C}(t)$. In (4) represents the system and converter voltages in terms of total resistance and total inductance. Applying Clark transformation in stationary reference frame to (4), (5) is derived.

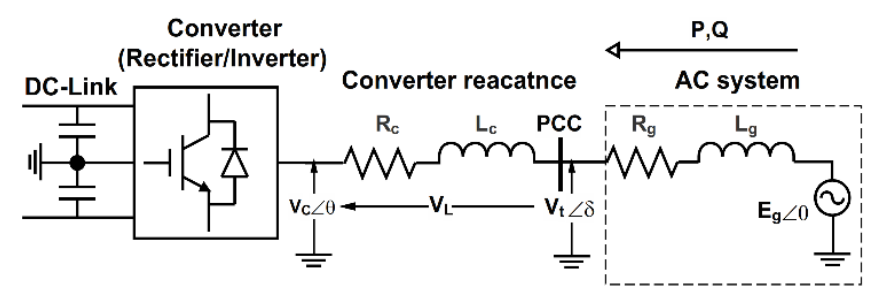

Figure 2. Single-line diagram of a grid connected VSC

$$
\begin{aligned}
& V_{t}(t)-V_{C}(t)=V_{L}(t) \\
& V_{t}(t)-V_{C}(t)=R_{C} i_{a b c}(t)+L_{C} \frac{d i_{a b c}(t)}{d t} \\
& V_{t_{\alpha \beta}}-V_{C \alpha \beta}=R_{C} i_{\alpha \beta}+L_{C} \frac{d i_{\alpha \beta}}{d t}
\end{aligned}
$$

As shown in (6) is drived through applying the Park's transformation to (5):

$$
V_{t_{d q}}-V_{C d q}=R_{C} i_{d q}+\omega L_{C} i_{d q}+L_{C} \frac{d i_{d q}}{d t}
$$

where $\omega$ is the grid frequency in $\mathrm{rad} / \mathrm{sec}$. 

written as:

Converting into $d-q$ synchronous reference farme, the converter output voltage equations can be

$$
\begin{aligned}
& V_{C d}=V_{t d}-R_{C} i_{d}-L_{C} \frac{d i_{d}}{d t}+\omega L_{C} i_{q} \\
& V_{C q}=V_{t q}-R_{C} i_{q}-L_{C} \frac{d i_{q}}{d t}-\omega L_{C} i_{d}
\end{aligned}
$$

where $V_{t d}$ and $V_{t q}$ are the d-q grid terminal voltages, $V_{C d}$ and $V_{C q}$ are the d-q grid side converter voltages, $i_{d}$ and $i_{q}$ are the d-q currents. The active and reactive power in complex form $(S)$ at the PCC is given by (9) in $\mathrm{d}-\mathrm{q}$ reference frame, where the sign $(*)$ represents the complex conjugation of the current vector.

$$
\begin{aligned}
S & =\frac{3}{2} V_{t d q} i_{d q}^{*}=\frac{3}{2}\left(V_{t d}+j V_{t q}\right)\left(i_{d}-j i_{q}\right) \\
& =\frac{3}{2}\left[\left(V_{t d} i_{d}+V_{t q} i_{q}\right)+j\left(V_{t q} i_{d}-V_{t d} i_{q}\right)\right]
\end{aligned}
$$

Hence at the PCC (AC side) measured active and reactive power of the VSC are given respectively by:

$$
\begin{aligned}
& P=\frac{3}{2}\left(V_{t d} i_{d}+V_{t q} i_{q}\right) \\
& Q=\frac{3}{2}\left(V_{t q} i_{d}-V_{t d} i_{q}\right)
\end{aligned}
$$

Therefore, when AC system is connected to a VSC, the d-q reference frame is used to make a fully active and reactive current decoupled linear control. At steady-state operation, active power exchange between grid side and DC-link will be equal as in (12), neglecting the losses due to the semiconductors.

$$
\begin{aligned}
P_{d c} & =P_{a c} \\
V_{d c} I_{d c} & =\frac{3}{2}\left(V_{t d} i_{d}+V_{t q} i_{q}\right)
\end{aligned}
$$

\subsection{AC grid model}

Thevenin's equivalent circuit is modelling the AC system connected to the VSC-HVDC system; where the $E_{g}$ represent the Thevenin's equivalent voltage and $Z_{g}$ represents equivalent impedance of the grid. However, VSC operation is mainly affected by the strength of the AC grid attached to it. Short circuit ratio (SCR) of the grid indicates the system According to literature short circuit ratio (SCR) is defined as the ratio of the grid short-circuit MVA to DC power as in (13) [20-22].

$$
S C R=\frac{S_{a c}}{P_{d c}}
$$

In normal operating conditions, AC grid usually has a high SCR (strong grid) for most of the time. During emergencies (generation outage, transmission outage and faults) system has a low SCR (weak grid). The AC grid high impedance indicates a weak AC system typically. As the impedance of the AC system increases, power variations of HVDC system senitivily change the voltage magnitude of the system. Therefore, the system under consideration will be tested for low SCR value $(\mathrm{SCR}=2)$ besides being connected to a heavily inductive loads that represent the nature of the industrial loads.

\subsection{Control strategy}

Control strategy will implement the vector control in $\mathrm{d}-\mathrm{q}$ synchronous reference frame. This will be applicable for both WPP side and AC grid side converter's stations. The control strategy will be as:

- WPP offshore power generation;

- Power transmission to the onshore station;

- Active and reactive power control through machine side station.

- The DC-voltage controller controls the active power injected into the grid, while the reactive power is controlled and provided through AC-voltage controller. 
To synchronize the d-q rotating frame of the converter with the rotating vector of the grid voltage abc-to-dq and dq-to-abc transformation is used with a phase-locked loop (PLL). The grid voltage magnitude has been aligned with $\mathrm{d}$-axis while the q-axis voltage is zero. The quadrature axis is forced to reach zero value $\left(V_{t d}=V_{t}\right.$ and $\left.V_{t q}=0\right)$ using proportional-integral controller (PI) as shown in Figure 3. The resulting active and reactive powers given by (10) and (11) became:

$$
\begin{aligned}
& P=\frac{3}{2} V_{t d} i_{d} \\
& Q=-\frac{3}{2} V_{t d} i_{q}
\end{aligned}
$$

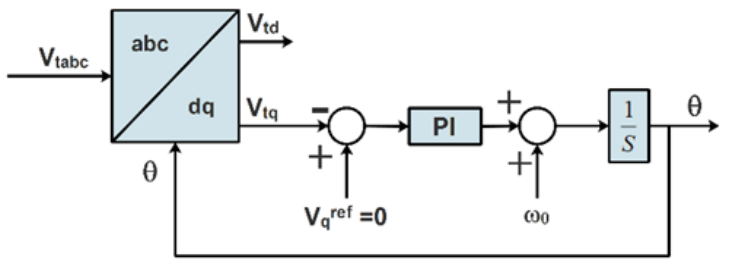

(a)

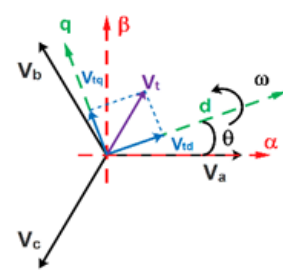

(b)

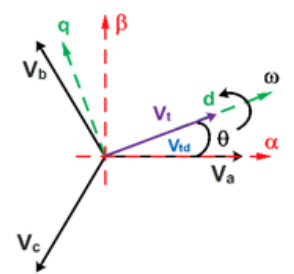

(c)

Figure 3. Grid terminal vector alignment on d-axis, a) phase locked loop block diagram,

b) misaligned vector, and c) aligned vector

\subsubsection{WPP offshore converter station:}

Controlling the $\mathrm{d}-\mathrm{q}$ axes currents will provide control to the active and reactive power directly as shown in Figure 4. The measured currents actual values $\left(i_{d 1}, i_{q 1}\right)$ are compared to the reference currents values $\left(\mathrm{i}_{\mathrm{d} 1}{ }^{\text {ref }}, \mathrm{i}_{\mathrm{q} 1}{ }^{\text {ref }}\right)$. These reference currents are obtained from (14) and (15) by dividing the reference active and reactive powers to $\left((3 / 2) \mathrm{V}_{\mathrm{d} 1}\right)$ as shown in Figure $4(\mathrm{a})$. The $\mathrm{d}-\mathrm{q}$ refrence voltages for the inductor are produced by two PI regualtors. This d-q reference voltage regulates the error signals, as in Figure 4 (b). The converter output-reference voltages $\left(\mathrm{V}_{\mathrm{Cd} 1}{ }^{\text {ref }}, \mathrm{V}_{\mathrm{Cq} 1}{ }^{\text {ref }}\right)$ are obtained by (7), (8). The two terms $\omega_{\mathrm{g}} \mathrm{LCi}_{\mathrm{d} 1}$ and $\omega_{\mathrm{g}} \mathrm{LCi}_{\mathrm{q} 1}$ compensate for the coupling between the $\mathrm{d}-\mathrm{q}$ axes. The switching pattern required of the IGBT modules is produced by comparing the PWM carrier signal to the converter voltages after transforme them back into the abc reference frame $\left(\mathrm{V}_{\mathrm{abcl}}{ }^{\text {ref }}\right)$.

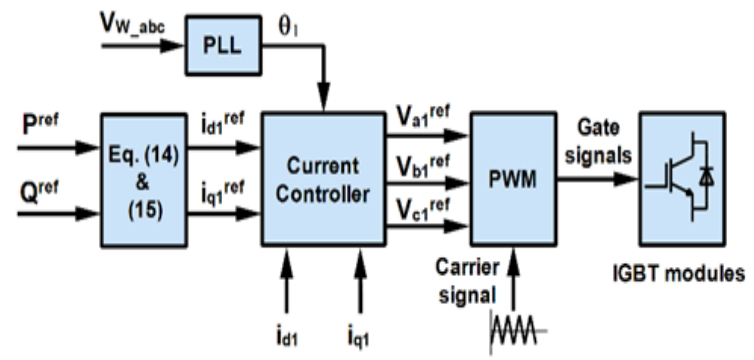

(a)

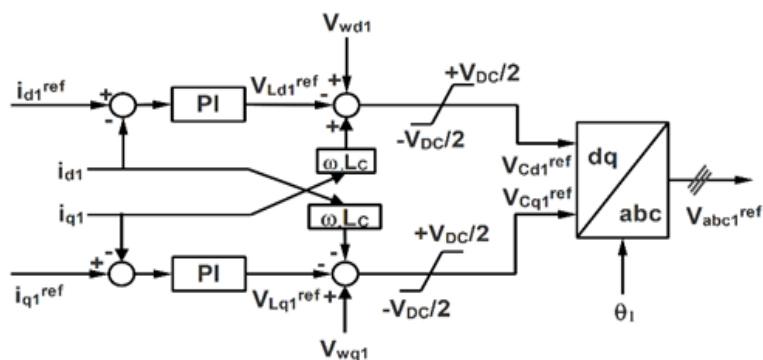

(b)

Figure 4. Closed loop control for the offshore rectifier station,

a) overall controller block diagram, b) current controller

\subsubsection{Grid side onshore converter station:}

The main control goal is to keep the rated value of the DC-link voltage constant. Controlling the daxis current will control the active power according to (12) (voltage will be aligned with d-axis, i.e. $V_{\mathrm{tg} 2}=0$ ) as shown in Figure 5. To control the reactive power, AC voltage controller controls the q-axis current of the current vector. The same procedures of obtainig the reference voltage were followed as in the offshore station. This provides the PWM modulator desired three-phase voltages references. Table 2 gives different control loops' gains. 


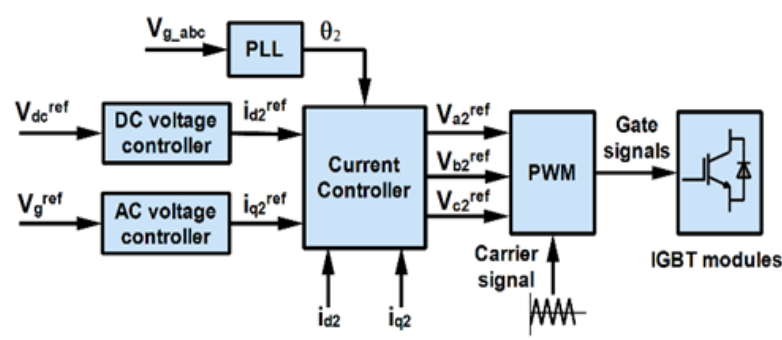

(a)

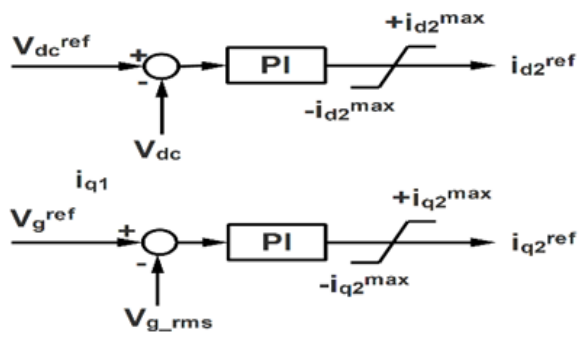

(b)

Figure 5. Closed loop control of the onshore inverter station, a) overall controller block diagram,

b) DC/AC voltage controller

Table 2. Proposed controller gains

\begin{tabular}{lcc}
\hline \multicolumn{1}{c}{ Controller Type } & $\mathrm{Kp}$ & $\mathrm{Ki}$ \\
\hline Current Controller & 546 & 8250.4 \\
DC-voltage Controller & 0.063 & 3.142 \\
AC-voltage Controller & 0.15 & 8 \\
Phase-locked loop (PLL) Controller & 230 & 115 \\
\hline
\end{tabular}

\section{SIMULATION RESULTS}

The behavior of the VSC-HVDC transmission system connected to weak AC grid only has been analyzed firstly. Followed by the performance evaluation of the system connected with industrial power system. The industrial power system modelled as two heavily inductive loads as shown in Figure 1 where load 1 is connected firstly then load 2 is added. The system was modelled using MATLAB/Simulink package where the IGBT modules needed to handle the current and voltage stress were simplified as one IGBT module for the top and another for the bottom half of each leg. The capacitor bank for the DC-link was simplified to one capacitor for the positive and negative DC-link voltage. The switching frequency has been chosen as $2.5 \mathrm{kHz}$.

\subsection{VSC-HVDC system connected to weak AC grid}

To evaluate the behaviour of the system connected to weak AC grid, the grid SCR value has chosen to be 2 with grid impedance angle of 7 (ratio of the grid reactance to the grid resistance X/R). Figure 6 shows the active and reactive powers at both converter stations where the active power of 1 p.u was sent from offshore station at $0.5 \mathrm{sec}$ as shown in Figure 6(a), the reactive power was kept at zero value. Figure 6(b) shows the active/reactive power at the grid side that equals 0.9 pu due to the losses on the transmission, the phase reactors and the transformers. The negative sign of the active power at the onshore station indicates injection of the power into the grid.

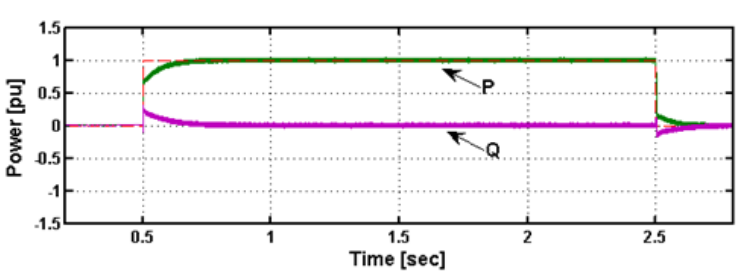

(a)

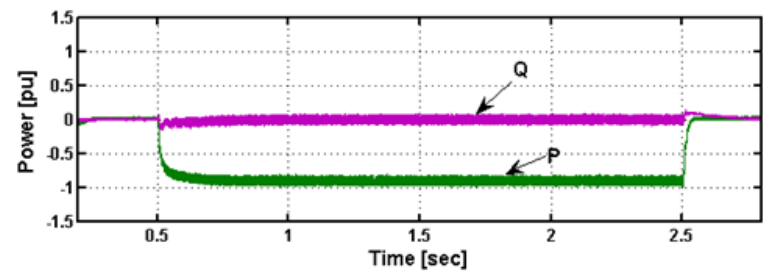

(b)

Figure 6. Active and reactive powers measured at converter stations, a) offshore station, b) onshore station

Figure 7 shows three-phase currents for each perspective station that start to flow at $0.5 \mathrm{sec}$ with fixed value (1 p.u) till the power reference back to zero at $2.5 \mathrm{sec}$ indicates that no variation has occurred on both stations. Figure 8 shows the resulted DC-link voltage, the simulated voltage at both stations follows the reference value at 1 p.u. The maximum overshoot occurred when the active power increase/decrease from the maximum power variation of 1 p.u that not exceeding the DC-link limits $( \pm 10 \%)$. Finally, current and voltage total-harmonic distortion (THD) at the PCC were found to be $4.20 \%$ and $1.53 \%$ respectively. These values 
comply with the IEEE-1547 standard for interconnecting distributed resources with electric power systems [23-25].

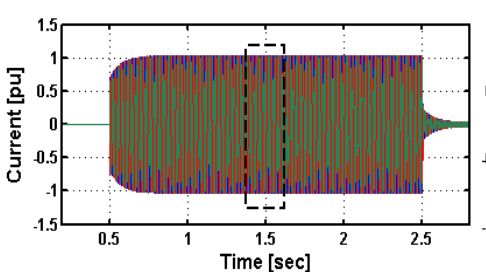

(a)

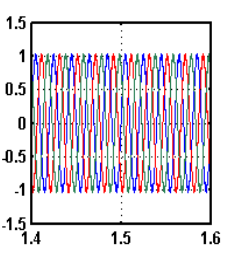

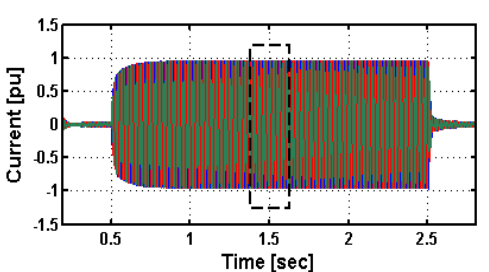

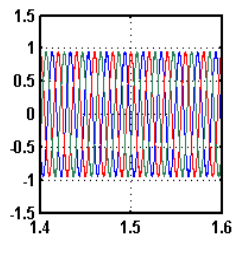

(b)

Figure 7. Measured three-phase currents at converter stations, a) offshore station, b) onshore station

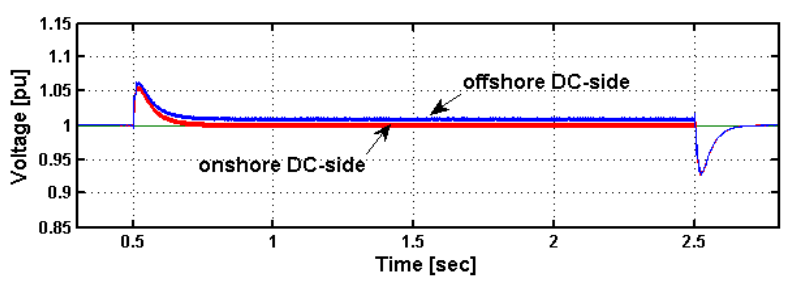

Figure 8. Measured three-phase currents at converter stations

\subsection{VSC-HVDC system connected to a weak industrial AC power grid}

Industrial power systems usually have high inductive behaviour due to its components nature. Industrial systems commonly consists of motors with different types that needs reactive power to operate. The supply voltage is affected by the amount of reactive power demand increase. On the other hand, voltage variation on the supply highly affect the grid strength. Figure 9 gives the voltage variation comparison between two different grids strengths supplying the same loads. To investigate the behaviour of controlled active and reactive powers, simulation time is discriticized into $0.5 \mathrm{~s}$ intervals. Two loading patterns were applied at different time intervals. The first load pattern, namely load 1 which has the value of $(\mathrm{P}=0.2 \mathrm{pu}$, $\mathrm{Q}=0.4 \mathrm{pu}$ ), was applied at $1 \mathrm{sec}$ of simulation time. While the second load, namely load $2 \mathrm{of}(\mathrm{P}=0.3 \mathrm{pu}, \mathrm{Q}=0.4 \mathrm{pu})$, was added at instatnt $1.5 \mathrm{sec}$ to $2 \mathrm{sec}$. At simulation time $2 \mathrm{sec}$, the two mentioned loads are disconnected. Figure 9 shows that grid voltage is less affected with loading when the gid strength is high. Voltage reached the value of $0.92 \mathrm{pu}$ when SCR equals 10 (strong grid). Minimum voltage value of $0.7 \mathrm{pu}$ was reached at weak grid condition loading $(\mathrm{SCR}=2)$. This indicates that strong grid is able to provide the reactive power necessary to maintain the voltage drop at certain amount. This reactive power helps the mitigation of voltage decrease at heavily industrial (inductive) loads. The proposed model was used to enhance the weak grid effect on voltage value for heavily industrial loads.

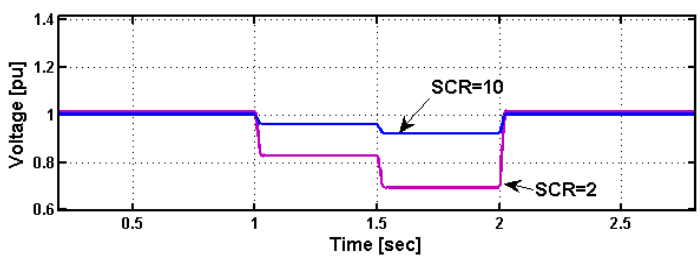

Figure 9. Effect of grid strength on voltage magnitude for heavily industrial loads

Figure10 shows the effcet of VSC-HVDC system attached to aweak AC grid with heavily industrial load on both active and reactive powers. The loading patterns described above were implemented. Four simulation intervals are studied as: 


\subsubsection{No-load $(0.5<t<1)$ :}

During this interval the only active power is sent to the grid terminal with zero value of reactive power where Figure 10(a) and Figure 10(b) are identical.

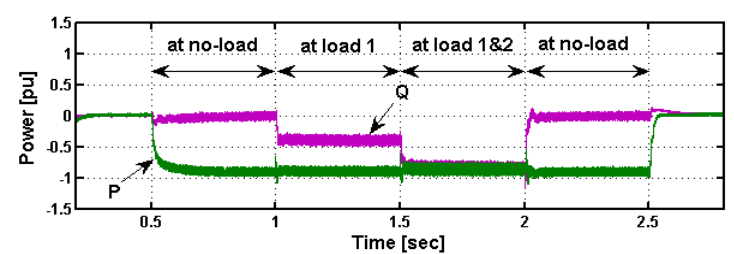

(a)

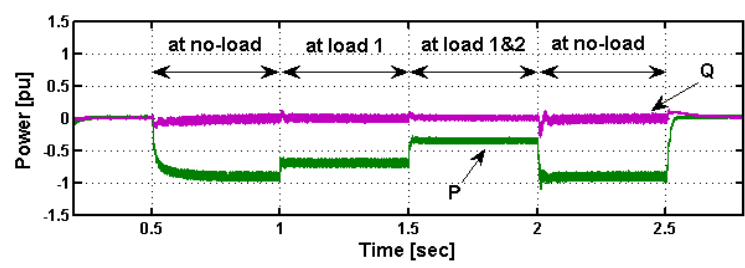

(b)

Figure 10. Active and reactive powers variation during loading, a) at VSC terminal, b) at PCC terminal

\subsubsection{Load $1(1<\mathrm{t}<1.5)$}

In this interval load 1 is connected to the PCC which made the controller of the VSC to supply the load 1 with the required active and reactive powers. Figure 10(a) shows a 0.4 pu increase of reactive power at the VSC terminal while the active power was kept at $-1 \mathrm{pu}$. At the PCC terminal, the reactive power remained fixed at zero value while the injected active power to the grid was reduced by the amount supplied to the load (0.2 pu) as shown in Figure 10(b).

\subsubsection{Load 1 and load $2(1.5<t<2)$}

In this interval, load 2 was added to the prevouis load with more reactive power supplied. As shown in Figure 10(a), the VSC controller of the onshore converter station respond fastly to change the reference of the reactive power to $-0.8 \mathrm{pu}$. The reference of the active power is kept unchanged at $-1 \mathrm{pu}$. The active power injected of $0.9 \mathrm{pu}$ at PCC decreased by $0.5 \mathrm{pu}$, leaving only $0.4 \mathrm{pu}$ to be transferred to grid. Figure 10(b) shows the variation of active and reactive powers with loading at different simulation times.

\subsubsection{No-load $(2<\mathrm{t}<2.5)$}

In this interval, the loads are disconected making the VSC controller to force the reactive power back to zero value at the VSC terminal as shown in Figure 10(a). The system retairned to inject the full active power again into the grid with no reactive power injecteion as shown in Figure 10(b). Three-phase currents variation, during loading, on both on and offshore stations are shown in Figure 11. The offshore station currents remain fixed at $1 \mathrm{pu}$ as unloaded condition, Figure 11(a). At the PCC, the measured injected current into the grid measured showed a decrease with load increase following the same behavior of the active power at the PCC.

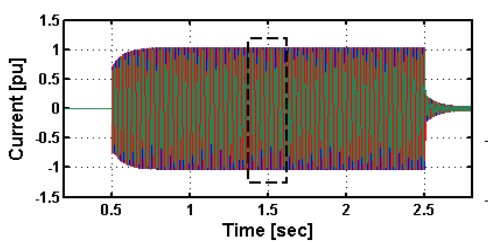

(a)
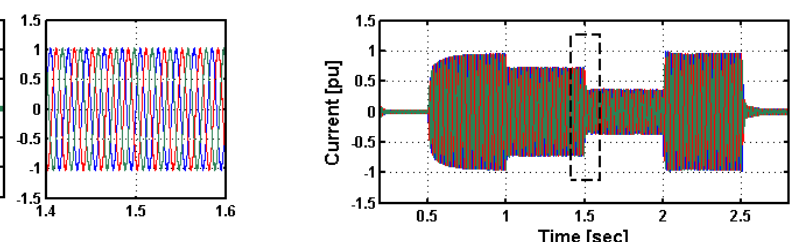

(b)

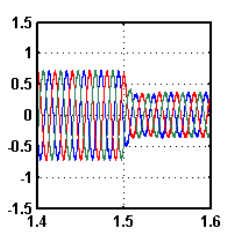

)

Figure 11. The change of three-phase currents at PCC during loading, a) offshore station, b) onshore station

Figure 12 shows the DC-link voltage variation under loading conditions. The DC-link voltage is kept at rated value of 1 pu. The maximum overshoot was found to be $\pm 5 \%$, which indicates a good performance of the DC voltage controller in tracking the reference with disturbance rejection. Figure 13 compares between the grid voltages at the PCC under different loads with/without the VSC-HVDC system. It is clear that with VSC-HVDC system the grid voltage sag due to loading has been mitigated. At full load, the voltage controller was able of improving the grid voltage value from 0.7 pu to $1 \mathrm{pu}$ with the integration of the VSC-HVDC system that operates as a STATCOM for reactive power compensation. 


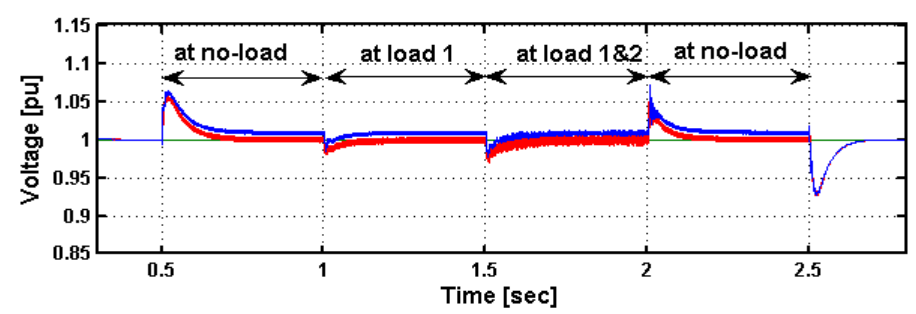

Figure 12. DC-link voltage during loading

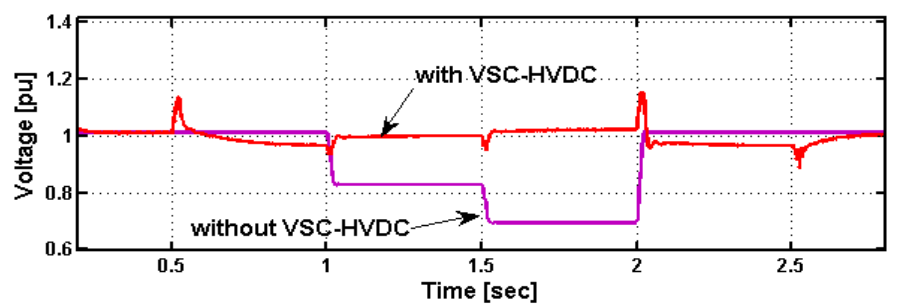

Figure 13. Variation of RMS grid voltage value at PCC during loading

\section{CONCLUSION}

This paper investigated the integration of offshore WPP to supply power to an AC grid with different loading conditions through VSC-HVDC transmission system. In addition, the paper investigated the effect of the grid strength for supplying a heavily industrial loads. It has been found that for industrial power systems the grid voltage is highly affected when it is attached to weak grids. The simulated model showed that with a SCR of 10 the grid voltage decreased to 0.92 pu only while with SCR of 2 the voltage decreased to $0.7 \mathrm{pu}$ for the same loads.

The paper proves that the use of VSC-HVDC transmission system to an AC weak grid, with heavy industrial loads, can help control the reactive power amount needed to keep the AC grid voltage within limits. Applying the proposed model, results ahowed that the grid voltage has been improved from 0.7 p.u to $1 \mathrm{pu}$ at full load. The grid voltage improvement through a different reactive power source other than the grid will help the absorbed reactive power to be reduced. This will reduce the current drawn from the grid, i.e less circuit breaker size, cables cross section, and losses. This will reduce the overall cost of the AC grid side installation.

\section{REFERENCES}

[1] G. W. E. Council, "Global wind energy outlook," GWEC, 2014.

[2] Flourentzou N., Agelidis V. G., and Demetriades G. D., "VSC-based HVDC power transmission systems: An overview," IEEE Transactions on Power Electronics, vol. 24, no. 3, pp. 592-602, 2009.

[3] J. Arrillaga, Y. H. Liu and N. R. Watson, "Flexible Power Transmission: The HVDC Options," West Sussex, U.K.: John Wiley \& Sons, 2007.

[4] O. Anaya-Lara, et al., "Offshore wind energy generation: Control, Protection and Integration to Electrical Systems," West Sussex, U.K.: John Wiley \& Sons, 2014.

[5] M. F. McGranaghan, D. R. Mueller and M. J. Samotyj, "Voltage sags in industrial systems," IEEE Transactions on Industry Applications, vol. 29, no. 2, pp. 397-403, 1993.

[6] C. J. Melhorn, T. D. Davis and G. E. Beam, "Voltage sags: their impact on the utility and industrial customers," IEEE Transactions on Industry Applications, vol. 34, no. 3, pp. 549-558, 1998.

[7] A. Sannino, M. G. Miller and M. H. J. Bollen, "Overview of voltage sag mitigation," IEEE Power Engineering Society Winter Meeting. Conference Proceedings (Cat. No.00CH37077), 2000, vol. 4, pp. 2872-2878.

[8] R. Arnold, "Solutions to the power quality problem," Power Engineering Journal, vol. 15, no. 2, pp. 65-73, 2001.

[9] K. Tatjana, "Control of Voltage Source Converters for Power System Applications," M.Sc. thesis, Norwegian University of Science and Technology, 2011.

[10] P. Haugland, "It's time to connect: Technical description of HVDC Light ${ }^{\circledR}$ technology," ABB Technical Report, 2008.

[11] R. F. Arritt and R. C. Dugan, "Distributed generation interconnection transformer and grounding selection," IEEE Power and Energy Society General Meeting-Conversion and Delivery of Electrical Energy in the 21st Century, pp. 1-7, 2008. 
[12] F. Wang, et al., "An Overview Introduction of VSC-HVDC: State-of-art and Potential Applications in Electric Power Systems," Proc. Cigrè Int. Symposium, Bologna, Italy, 2011.

[13] P. Zhou, et al., "Stability of DC-link voltage as affected by phase locked loop in vsc when attAChed to weak grid," IEEE PES General Meeting | Conference \& Exposition, pp. 1-5, 2014.

[14] L. R Limongi, et al., "Analysis and Comparison of Phase Locked Loop Techniques for Grid Utility Applications," Power Conversion Conference - Nagoya, Nagoya, 2007, pp. 674-681.

[15] R. Rudervall, et al., "High Voltage Direct Current (HVDC) Transmission Systems Technology Review Paper," IEEE Energytech, Cleveland, 2012, pp. 1-7.

[16] L. Weimers, "New markets need new technology," PowerCon 2000. 2000 International Conference on Power System Technology. Proceedings (Cat. No.00EX409), 2000, vol. 2, pp. 873-877.

[17] Krause, Paul C., et al., "Analysis of electric machinery and drive systems," West Sussex, U.K.: John Wiley \& Sons, 2nd edition, 2002.

[18] J. M. Rodrigues, F. Resende, and C. Moreira, "Contribution of PMSG based small wind generation systems to provide voltage control in low voltage networks," 2nd IEEE PES International Conference and Exhibition on Innovative Smart Grid Technologies, 2011, pp. 1-8.

[19] X. Guo, W. Wu and H. Gu, "Phase locked loop and synchronization methods for grid interfaced converters: a review," Przeglad Elektrotechniczny, vol. 87, no. 4, pp. 182-187, 2011.

[20] Krishayya, P. C. S., R. Adapa, and M. Holm., "IEEE guide for planning DC links terminating at AC locations having low short-circuit capacities," IEEE Std 1204-1997, pp. 1-216, 1997.

[21] P. J. D. Chainho, et al., "General Modeling of Multi-terminal VSC-HVDC Systems for Transient Stability Studies," Proc. 6th IEEE Young Researchers Symposium in Electrical Power Engineering, Delft, Netherlands, 2012.

[22] Z. Wu, X. Dou, J. Chu and M. Hu, "Operation and control of a direct-driven PMSG-based wind turbine system with an auxiliary parallel grid-side converter," Energies, vol. 6, no. 7, pp. 3405-3421, 2013.

[23] Photovoltaics, Dispersed Generation, and Energy Storage, "IEEE application guide for IEEE STD 1547(tm), IEEE standard for interconnecting distributed resources with electric power systems," IEEE STD 1547.2-2008, pp. 1-217, 2009.

[24] Ahmed F. Abouzeid, Ahmed A. Daoud, Sobhy S. Dessouky and Juan M. Guerrero, "Factors Affecting Offshore Wind Power Integration to Grid through VSC-HVDC," Eighteenth International Middle East Power Systems Conference (MEPCON), 2016, pp. 184-189.

[25] Ahmed F. Abouzeid, Ahmed A. Daoud, Sobhy S. Dessouky, "Implementation Of Vector Control For Grid Voltage Support In Vsc-Hvdc Transmission System," Journal of Electrical Engineering, vol. 17, pp. 352-358, 2017

\section{BIOGRAPHIES OF AUTHORS}

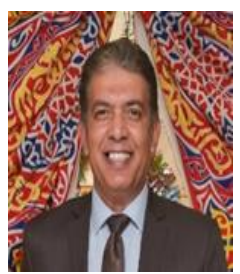

Ahmed A. Daoud is an Associate Professor with Ee Dept., Port Said University, Egypt. His research interests are renewable energy, network anlysis, power system stability, demand side management and smart grid applications. He is the ceo of the egyptian engineering association, port said branch. $\mathrm{He}$ is currently working in a research project involving micro grids incorporating renewable resources and ev to enhance grid energy management and control.

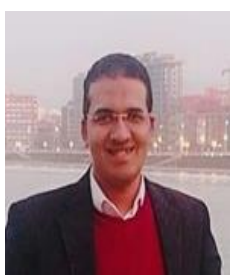

Ahmed F. Abouzeid is a Ph.D. student and research assistant with Ee Dept., Port Said University, Egypt. He got his master in electrical engineering in 2016. his research titles investigation of multiterminal voltage source converter hvdc for wind power integration this work was a part of his ms.c thesis.

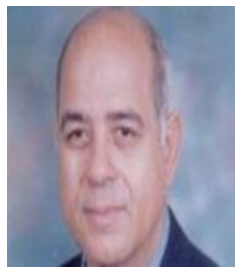

Sobhy S. Dessouky is a Professor with Ee Dept, Port Said University, Egypt. his research interests are high voltage technology, renewable energy, network analysis and smart grid technology. he has a lot of experience in research projects and he is currently working in a research project involving micro grids incorporating renewable resources and ev to enhance grid energy management and control. 